\title{
O CONCEITO DO DUMPING PARA A REGULAMENTAÇÃO MULTILATERAL DO COMÉRCIO INTERNACIONAL
}

Marlon Tomazette*

\section{Introdução}

A prática do dumping pode autorizar medidas protecionistas no âmbito do comércio internacional, por isso, é fundamental entender o que vem realmente a ser o dumping. Vale ressaltar que o termo dumping foi e ainda é usado em vários sentidos, na linguagem comercial, designando inclusive práticas que não representam tecnicamente o dumping, sendo fundamental afastar tal confusão terminológica. Coube aos estudos econômicos as primeiras formulações mais científicas de um conceito de dumping, chegandose a idéia geral de uma discriminação de preços entre diferentes mercados nacionais.

Tal conceito econômico, contudo, não se confunde com o conceito jurídico que veio a ser formulado posteriormente em termos legais, pelo Acordo Antidumping (AAD), como a exportação de um produto a preços inferiores ao seu valor normal. Vê-se a partir do conceito legal os contornos fundamentais da prática do dumping para qualquer análise jurídica do instituto. Todavia, tal conceito legal faz menção a diversos outros conceitos que precisam ser entendidos.

A partir desse conceito, é fundamental distinguir a prática de dumping de outras práticas como o preço predatório e o underselling que além de se referirem mais ao comércio interno que ao internacional, possuem contornos bem distintos.Outrossim, é certo que com o passar do tempo, acabaram surgindo novas práticas identificadas como tipos de dumping, assim os chamados dumping cambial, dumping social e o dumping ambiental. Tais "novos tipos” de dumping possuem contornos próprios que são bem diferentes dos contornos

\footnotetext{
* Advogado, procurador do Distrito Federal, professor de direito comercial do Centro Universitário de Brasília UNICEUB e da Escola Superior do Ministério Público do Distrito Federal e Territórios. Mestrando do Programa de Mestrado em Direito do UniCEUB, área de concentração Relações Internacionais. E-mail : marlon@opendf.com.br
} 
delineados no Acordo Antidumping, restando assim saber se eles, na realidade configuram ou não a prática do dumping.

\section{A construção de um conceito econômico de dumping}

O nome dumping, em si, pode ter se originado do islandês arcaico thumpa (atingir alguém), tendo sido utilizado, também, como sinônimo para depósito temporário de munições ${ }^{1}$. No inglês moderno, o verbo to dump significa despejar, descarregar, desfazer-se de algo ou jogar fora ${ }^{2}$.

O termo dumping foi e ainda é usado em vários sentidos, designando inclusive práticas que não representam tecnicamente o dumping. Muitos comerciantes estendem o uso de tal expressão para qualquer vendo abaixo do preço usual, ainda que haja uma uniformidade do preço para todos os compradores. Assim, vê-se que inicialmente, usava-se tal expressão para designar diversas condutas, como subvalorização de mercadorias, barganha, sacrifícios, vendas abaixo do preço, discriminação de preços, ou ainda corte de preços no mercado local ${ }^{3}$, idéias que ainda hoje são usadas, mas não representam a prática do dumping.

Inicialmente na Economia, entendia-se a prática do dumping como qualquer prática desleal de comércio internacional considerada perigosa para a economia do país importador ${ }^{4}$. Aos poucos se reduziu o âmbito desse conceito, para práticas ligadas ao preço de mercadorias. Daí, o dumping passou a ser entendido freqüentemente como a venda da mesma mercadoria em diferentes mercados, por preços diferentes ${ }^{5}$. Desse uso inicial, pode-se constar a presença de alguns elementos comuns, em todas as acepções usadas. Nessa concepção inicial, três elementos o caracterizam: a) a relação com uma prática desleal de comércio; b) a manutenção da expressão original em inglês e c) uma conotação sempre pejorativa, como um comportamento negativo ou condenável ${ }^{6}$.

\footnotetext{
${ }^{1}$ MARCEAU, Gabrielle. Anti-dumping and anti-trust issues in free trade areas. Oxford: Clarendon Press, 1994, p. 7; BARRAL, Welber Oliveira. Dumping e comércio internacional: a regulamentação antidumping após a rodada Uruguai. Rio de Janeiro: Forense, 2000, p. 8.

2 ALLEN, Robert (publishing Director). Essential English Dictionary. São Paulo: Chambers Martins Fontes, 1999, p. 288.

${ }^{3}$ VINER, Jacob. Dumping: a problem in international trade. Chicago: University of Chicago Press, 1923 , p. 1.

${ }^{4}$ ROJAS AMANDI, Victor Manuel. EI derecho antidumping de la Unión Europea. México: Porruá, 2004 , p. 5.

${ }^{5}$ VINER, Jacob. Dumping: a problem in international trade. Chicago: University of Chicago Press, 1923, p. 2; MARCEAU, Gabrielle. Anti-dumping and anti-trust issues in free trade areas. Oxford: Clarendon Press, 1994, p. 11.

${ }^{6}$ BARRAL, Welber. Dumping e comércio internacional: a regulamentação antidumping após a Rodada Uruguai. Rio de Janeiro: Forense, 2000, p. 7-8.

PRISMAS: Dir., Pol.Pub. e Mundial., Brasília, v.4, n, 1, p 194-214, jan/jul. 2007 
Posteriormente tal termo passou a ser usado de forma mais técnica, inicialmente na Economia que, na busca de uma terminologia mais exata, formulou um conceito sem a preocupação de abranger todos os usos correntes da palavra. Assim, pode-se dizer que se trata de uma “discriminação de preços entre dois mercados nacionais, entre o mercado exportador e o mercado importador. Em outras palavras, o preço demandado por um determinado bem, pelo mesmo produtor, difere entre dois mercados, desconsiderando-se os fatores relacionados a transporte, tributos etc." ${ }^{7}$.

Viner afirmou que a característica essencial do dumping é a “discriminação de

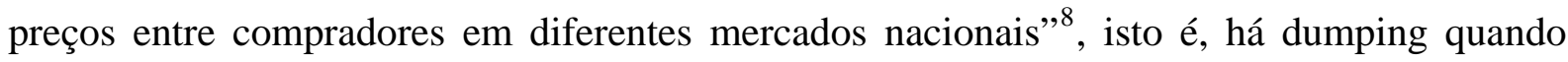
ocorre a venda da mesma mercadoria por diferentes preços a diferentes mercados, sem razões associadas com diferenças de custos, ou ainda quando são vendidos pelo mesmo preço, mas há diferenças de custos ${ }^{9}$. Para ele, as intrincadas relações entre do dumping com os custos de produção, com os proveitos gerados e com os preços dos concorrentes não devem ser abrangidas no conceito. Normalmente, o dumping é praticado em um mercado ocasional ou secundário, mantendo-se o preço mais elevado no mercado principal, no qual o produtor tem condições de fixar o preço ${ }^{10}$. Todavia, tal situação pode ser invertida em determinadas momentos específicos.

A condição necessária para a configuração do dumping é a possibilidade de divisão do mercado em vários submercados, podendo-se isolar ao menos um deles dos demais ${ }^{11}$, por motivos sociais, geográficos culturais ou legais ${ }^{12}$. Além disso, deve haver uma diferença de competitividade entre os dois mercados, para permitir a discriminação de preços, vale dizer, a elasticidade da demanda e a oferta devem ser diferentes ${ }^{13}$.

No conceito dado, abrange-se a situação mais comum do dumping, quando se realizada uma exportação por um preço inferior ao do mercado doméstico, mas também

\footnotetext{
${ }^{7}$ BARRAL, Welber. Medidas Antidumping. In: (Org). O Brasil e a OMC. 2. ed. Curitiba: Juruá, 2004, p. 217.

${ }^{8}$ VINER, Jacob. Dumping: a problem in international trade. Chicago: University of Chicago Press, 1923, p. 4, tradução livre de "price-discrimination between purchasers in different national markets".

9 MARCEAU, Gabrielle. Anti-dumping and anti-trust issues in free trade areas. Oxford: Clarendon Press, 1994, p. 11.

${ }^{10}$ ROJAS AMANDI, Victor Manuel. El derecho antidumping de la Unión Europea. México: Porruá, 2004, p. 7.

${ }^{11}$ BAPTISTA, Luiz Olavo. Dumping e Anti-dumping no Brasil. In: AMARAL JÚNIOR, Alberto do (Coord). OMC e o comércio internacional. São Paulo: Aduaneiras, 2002, p.30; ROJAS AMANDI, Victor Manuel. EI derecho antidumping de la Unión Europea. México: Porruá, 2004, p. 7.

12 MARCEAU, Gabrielle. Anti-dumping and anti-trust issues in free trade areas. Oxford: Clarendon Press, 1994, p. 11.

${ }^{13}$ MARCEAU, Gabrielle. Anti-dumping and anti-trust issues in free trade areas. Oxford: Clarendon Press, 1994, p. 12.

PRISMAS: Dir., Pol.Pub. e Mundial., Brasília, v.4, n, 1, p 194-214, jan/jul. 2007 
outras situações mais raras. Quando não há ou é insignificante o mercado doméstico, há uma discriminação entre mercados exportadores também se configuraria o dumping. Além disso, também se enquadraria no conceito a situação de venda no mercado interno a preço inferior ao do mercado externo ${ }^{14}$.

Assim, quando um produtor que não possui mercado doméstico, discrimina entre dois mercados de exportação, está realizado dumping no mercado do país, no qual a venda se dá pelo preço mais baixo ${ }^{15}$. Do mesmo modo, se o mercado interno é insignificante e se faz a distinção entre dois mercados externos. Além disso, o dumping poderia ser praticado no mercado doméstico, vendendo os produtos neste âmbito a preços inferiores àqueles vendidos no mercado externo, configurando o chamado dumping reverso ${ }^{16}$.

\section{Conceito jurídico de dumping}

A acepção econômica do termo não corresponde exatamente a acepção jurídica ${ }^{17}$, que leva em conta a discriminação de preços entre mercados, mas também considera outros aspectos, em especial o valor normal da mercadoria, totalmente ignorado na formulação econômica do conceito.

A doutrina chega a conceituar a afirmar que o dumping consiste "na colocação de mercadorias em outro país a preço inferior daquele colocado no mercado doméstico, com o fito de desestabilizar a concorrência” ${ }^{18}$. Todavia, os motivos para tal conduta são os mais variados e, por isso, não é possível incluir a finalidade de tal prática no conceito que, em última análise, se torna um conceito objetivo. Basta que o preço de exportação seja inferior ao preço no mercado doméstico, independentemente da intenção.

A definição jurídica do dumping é dada pelo artigo VI do GATT ${ }^{19} 1994$. No Acordo Antidumping da rodada Uruguai ${ }^{20}$ a prática do dumping é conceituada, nos termos do

${ }^{14}$ VINER, Jacob. Dumping: a problem in international trade. Chicago: University of Chicago Press, 1923 , p. 5.

${ }^{15}$ BAPTISTA, Luiz Olavo. Dumping e Anti-dumping no Brasil. In: AMARAL JÚNIOR, Alberto do (Coord). OMC e o comércio internacional. São Paulo: Aduaneiras, 2002, p.30.

${ }^{16}$ VINER, Jacob. Dumping: a problem in international trade. Chicago: University of Chicago Press, 1923 , p. 6.

${ }^{17}$ ARRUDA, Gustavo Fávaro. Entendendo o dumping e o direito antidumping. Revista do IBRAC, São Paulo, v. 12, n. 6, p. 12, 2005; BAPTISTA, Luiz Olavo. Dumping e Anti-dumping no Brasil. In: AMARAL JÚNIOR, Alberto do (Coord). OMC e o comércio internacional. São Paulo: Aduaneiras, 2002, p. 30.

18 GUEDES, Josefina Maria M. M. e PINHEIRO, Sílvia M. Antidumping, subsídios e medidas compensatórias. 3. ed. São Paulo: Aduaneiras, 2002, p. 20.

${ }^{19}$ General Agreement on tariffs and Trade 94 ou Acordo Geral Sobre Tarifas e Comércio - “Art. VI - Para as finalidades do presente acordo, considera-se haver prática de dumping, isto é, oferta de um produto no comércio de outro país a preço inferior ao seu valor normal, no caso de o preço de exportação do produto ser inferior àquele praticado, no curso normal das atividades comerciais, para o mesmo produto quando destinado ao consumo do país exportador”.

PRISMAS: Dir., Pol.Pub. e Mundial., Brasília, v.4, n, 1, p 194-214, jan/jul. 2007 
artigo 2.1, como o caso de "produto introduzido no mercado por um preço inferior ao seu valor normal, preço comparável, no curso normal das atividades comerciais, do produto similar quando destinado para consumo do país exportador”. Nesta norma, a conceituação jurídica do dumping é um pouco mais detalhada, mas mantém a idéia geral de venda de um produto a preços inferiores ao seu valor normal, destacando-se que esse valor normal é o valor do produto quando destinado a consumo no país exportador em condições normais de comércio. Neste particular, o acordo traz mais adiante outros elementos que permitam essa comparação.

Na legislação brasileira sobre a matéria, o art. $4^{\circ}$ do Decreto $n^{\circ} 1.602 / 95$ afirma que "para os efeitos deste Decreto, considera-se prática de dumping a introdução de um bem no mercado doméstico, inclusive sob a modalidade de $d_{r a w b a c k}{ }^{21}$, a preço de exportação inferior ao valor normal”. Como não poderia deixar de ser, a legislação nacional mantém a mesma idéia fundamental sobre a acepção jurídica do dumping, como uma exportação de produtos para o Brasil com preço de exportação, inferior ao seu valor normal. Nesse conceito, destaca-se que qualquer tipo de exportação para o mercado brasileiro, ainda que com a finalidade de futuras exportações pode dar margem a configuração do dumping.

Tanto doutrinariamente quanto nos textos legais, vê-se que a definição econômica de dumping é mais ampla que sua acepção jurídica. Na primeira, basta a existência de discriminação de preços entre mercados distintos, ainda que o produto seja vendido pelo seu valor normal ou acima, vale dizer, o fundamental é uma discriminação injustificada de preços. Por outro lado, na acepção jurídica também é fundamental uma discriminação de preços, mas não qualquer discriminação entre dois mercados, isto é, no conceito jurídico é fundamental que essa discriminação ocorra com a venda de um produto por preços inferiores aos seus valores normais, apurados no mercado doméstico do país exportador, ou em outro similar, na impossibilidade de se comparar o valor naquele mercado.

Em suma, há dumping quando o preço de exportação de um produto é inferior ao seu valor normal ${ }^{22}$, em tese podendo haver prejuízo, vale dizer, o dumping ocorre quando há venda de bens em um mercado por preços inferiores aos preços inferiores aos preços

\footnotetext{
${ }^{20}$ Agreement on the implementation of Article VI of General Agreement on tariffs and Trade 1994 ou simplesmente Acordo antidumping (AAD) como será daqui em diante identificado.

${ }^{21}$ Benefí́cio fiscal concedido às importações realizadas com a finalidade de futuras exportações.

${ }^{22}$ HOEKMAN, Bernard M.; KOSTECKI, Michel M. The political economy of the world trading system: the WTO and beyond. 2 ed. Oxford: University Press, 2001. p. 315.

PRISMAS: Dir., Pol.Pub. e Mundial., Brasília, v.4, n, 1, p 194-214, jan/jul. 2007 
praticados no mercado doméstico, para produtos similares ${ }^{23}$, em condições normais de comércio. O dumping juridicamente guarda relação com a exportação de mercadorias, diferentemente de outros institutos como o preço predatório, exigindo para sua configuração que tal exportação seja realizada por um preço menor do que preço normalmente praticado para a venda de tal produto.

\section{Natureza jurídica do dumping}

A prática do dumping, em sua acepção, é uma realidade comum que, para fins didáticos, é incluída em certa categoria jurídica para facilitar o seu estudo, o que nem sempre é tarefa fácil. Ocorre que a tentativa de definir a natureza jurídica do dumping esbarra em certos empecilhos, a saber: a) trata-se de um fenômeno eminentemente econômico que, nem sempre, se adequa às categorias jurídicas; b) trata-se de um fenômeno recente e, por isso, não se enquadraria facilmente em categorias jurídicas já consolidadas; c) sua regulamentação é uma adaptação da legislação do common law e não fácil seu enquadramento em categorias da tradição da civil law ${ }^{24}$.

Com tais alertas, vale a pena estudar como a doutrina tenta enquadrar a prática dumping em uma categoria. Neste particular, há certa divergência doutrinária quanto à categorização de tal prática, destacando-se três opiniões que enquadram o dumping como ato ilícito $^{25}$, como um abuso do poder econômico ${ }^{26}$ ou ainda como fato econômico jurídico de direito internacional econômico.

$\mathrm{O}$ ato ilícito pode ser conceituado como aquele contrário à ordem jurídica e por ela reprovado, que importa uma sanção para o seu autor ${ }^{27}$, em razão dos danos causados. No Código Civil de 2002, tal conceito é sintetizado nos artigos 186 e 187 representando, em suma, uma conduta que viola um dever pré-existente, previsto no direito objetivo, bem como

${ }^{23}$ OSTONI, Lucia. Anti-dumping circumvention in the EU and the US: is there a future for multilateral provisions under the WTO? Fordham Journal of Corporate \& Financial Law, Vol. 10 Issue 2, 2005, p. 407.

${ }^{24}$ BARRAL, Welber. Dumping e comércio internacional: a regulamentação antidumping após a Rodada Uruguai. Rio de Janeiro: Forense, 2000, p. 47.

${ }^{25}$ MARQUES, Frederico do Valle Magalhães. O “Dumping” na Organização Mundial do Comércio e no Direito Brasileiro - Decreto 1.602/65. In: CASELLA, Paulo Borba e MERCADANTE, Araminta de Azevedo (Coord). Guerra comercial ou integração mundial pelo comércio? A OMC e o Brasil. São Paulo: Ltr, 1998, p. 299.; GOYOS JÚNIOR, Durval Noronha et al. Tratado de defesa comercial: antidumping, compensatórias e salvaguardas. São Paulo: Observador Legal, 2003, p. 7.

${ }^{26}$ POPP, Carlyle e ABDALA, Edson Vieira. Comentários à nova lei antitruste. 2 ed. Curitiba: Juruá, 1997, p. 36; CRETELLA JÚNIOR, José. Comentários à lei antitruste. 2.ed. Rio de Janeiro: Forense, 1996, p. 79.

${ }^{27}$ PINTO, Carlos Alberto da Mota. Teoria geral do Direito Civil. 3. ed. Coimbra: Coimbra, 1999, p. 354.

PRISMAS: Dir., Pol.Pub. e Mundial., Brasília, v.4, n, 1, p 194-214, jan/jul. 2007 
o direito subjetivo de outrem ${ }^{28}$, causando dano a este e fazendo surgir a obrigação de reparar os danos causados. Desse conceito, pode-se extrair os elementos fundamentais de um ato para ser enquadrado como ilícito: a conduta, a contrariedade ao direito e o prejuízo.

Ora, o dumping não é em si proibido, o que a legislação permite é a tomada de medidas caso o dumping praticado possa afetar a indústria nacional, ou seja, não se trata de uma conduta contrária ao direito e por isso, não se pode enquadrá-la de modo definitivo como um ato ilícito ${ }^{29}$. E mesmo o dumping condenável não pode ser tratado como um ato ilícito, pois a aplicação de medidas antidumping é um ato discricionário, ou seja, pode ou não ser tomada, de modo que não se pode vislumbrar na prática do dumping uma conduta que gere a obrigação de indenizar ${ }^{30}$.

Já o abuso do poder econômico representa “toda ação ou manobra do empresário ou de seu representante legal que, dominando o mercado e a concorrência tenha por objetivo a obtenção de lucros excessivos, causando danos” ${ }^{31}$. Trata-se de um uso anormal, ilegítimo, reprovável e imoral da liberdade econômica, que deve ser reprimido ${ }^{32}$. Tal abuso para ser reprimido deve objetivar a dominação dos mercados, a eliminação da concorrência ou o aumento arbitrário dos lucros, nos termos do artigo 173, § $4^{\circ}$ da Constituição Federal $^{33}$.

Mais uma vez, o dumping não pode se enquadrar nessa categoria, porquanto nem sempre o dumping tem por objetivo a dominação de mercados, a eliminação da concorrência ou o aumento arbitrário dos lucros ${ }^{34}$. Os objetivos de tal prática podem ser os mais diversos, não se limitando às hipóteses de abuso do poder econômico. Outrossim, é certo que a própria lei 8.884/94 que reprime os abusos do poder econômico afasta, em seu artigo 91, o dumping da sua regência, o que corrobora a sua não submissão a tal categoria jurídica.

Por fim, resta a inclusão do dumping na categoria fato jurídico econômico, isto é, trata-se de um fato capaz de criar, modificar ou extinguir direitos, que se realiza e produz efeitos na economia, submetendo-se ao direito econômico e legitimando a intervenção

${ }^{28}$ RÁO, Vicente. Ato jurídico. 4. ed. São Paulo: RT, 1997, p. 35; GAGLIANO, Pablo Stolze e PAMPLONA FILHO, Rodolfo. Novo curso de Direito Civil: parte geral. 2. ed. São Paulo: Saraiva, 2002, v. 1, p. 461-462.

${ }^{29}$ BARRAL, Welber. Dumping e comércio internacional: a regulamentação antidumping após a Rodada Uruguai. Rio de Janeiro: Forense, 2000, p. 47.

${ }^{30}$ BARRAL, Welber. Dumping e comércio internacional: a regulamentação antidumping após a Rodada Uruguai. Rio de Janeiro: Forense, 2000, p. 48.

${ }^{31}$ CRETELLA JÚNIOR, José. Comentários à lei antitruste. 2.ed. Rio de Janeiro: Forense, 1996, p. 13.

${ }^{32}$ FORGIONI, Paula A. Os fundamentos do antitruste. São Paulo: RT, 1998, p. 279.

${ }^{33}$ SALOMÃO FILHO, Calixto. Direito concorrencial: as condutas. São Paulo: Malheiros, 2003, p. 110-111.

${ }^{34}$ BARRAL, Welber. Dumping e comércio internacional: a regulamentação antidumping após a Rodada Uruguai. Rio de Janeiro: Forense, 2000, p. 48; LEÃES, Luiz Gastão Paes de Barros. O “dumping” como forma de abuso do poder econômico. Revista de Direito Mercantil, Industrial, Econômico e Financeiro. São Paulo, v. 32, n. 91, p. 13, jul./set. 1993.

PRISMAS: Dir., Pol.Pub. e Mundial., Brasília, v.4, n, 1, p 194-214, jan/jul. 2007 
estatal $^{35}$. Tal comportamento encontra seu fundamento em normas de direito internacional econômico já citadas e autoriza a intervenção estatal para a tomada de medidas antidumping, com o intuito de proteger a eficiência produtiva da indústria nacional ${ }^{36}$.

\section{Preço predatório e dumping}

A prática do dumping é uma realidade freqüente, assim como outras práticas comerciais. Todavia, por vezes, faz-se confusão do dumping com outras práticas comerciais, o que não deve ocorrer, porquanto, ainda que semelhantes, o dumping não se confunde com estas outras práticas, especialmente sob o ponto de vista jurídico. Uma das práticas mais confundidas com o dumping é o preço predatório.

O CADE - Conselho Administrativo de Defesa Econômica, em sua função de reprimir as infrações à ordem econômica, editou a resolução 20/99 que afirma ser o preço predatório a "prática deliberada de preços abaixo do custo variável médio, visando eliminar concorrentes para, em momento posterior poder praticar preços e lucros mais próximos do nível monopolístico”. Similar é a definição dada pela SEAE - Secretaria de Acompanhamento Econômico que assevera, na Portaria 70/2002, que o preço predatório representa a prática de "venda injustificada da mercadoria abaixo do preço de custo que produza efeitos ou tenha como objeto prejudicar a livre concorrência, dominar mercado relevante de bens e serviços, aumentar arbitrariamente os lucros ou exercer de forma abusiva posição dominante”.

Na doutrina brasileira, diz-se que

Preços predatórios são reduções de preços cuja lucratividade somente pode ser explicada a partir de uma estratégia de obter poder de mercado por meio da eliminação ou da disciplina (inibição das condutas competitivas) de um rival efetivo ou potencial, isto é, preços predatórios são preços que maximizaram lucros somente em função de seus efeitos exclusionários ou anticompetitivos (aumento de preços no longo prazo e redução das quantidades ofertadas $)^{37}$.

Na doutrina norte-americana conceitua-se o preço predatório como “a tentativa de um produtor de tirar um competidor dos negócios ou desencorajar a sua entrada no mercado,

\footnotetext{
${ }^{35}$ BARRAL, Welber. Dumping e comércio internacional: a regulamentação antidumping após a Rodada Uruguai. Rio de Janeiro: Forense, 2000, p. 49.

${ }^{36}$ BARRAL, Welber. Dumping e comércio internacional: a regulamentação antidumping após a Rodada Uruguai. Rio de Janeiro: Forense, 2000, p. 50.

${ }^{37}$ FAGUNDES, Jorge e KANCZUK, Fabio. Preços predatórios: testes e avanços recentes. Revista do IBRAC, São Paulo, v. 13, n. 2, p. 37, 2006.

PRISMAS: Dir., Pol.Pub. e Mundial., Brasília, v.4, n, 1, p 194-214, jan/jul. 2007 
pela venda dos seus produtos a um preço artificialmente baixo”38. Vê-se em qualquer conceito, que se trata de uma redução de preços, a princípio inexplicável, mas com o intuito de eliminar concorrentes.

Tal prática gera prejuízos imediatos para a empresa que age com o intuito predatório. Em função disso, tal prática só se mostra interessante para uma empresa que possui um razoável poder econômico ${ }^{39}$, suportando as perdas momentâneas para, no futuro, ter benefícios com a eliminação da concorrência. Além disso, é certo que os concorrentes não devem ser tão fortes, de modo que possam ser eliminados pelos preços predatórios. Outrossim, tal prática deve poder ser bem planejada, isto é, deve ter um prazo para produzir os efeitos desejados, os quais, no futuro, deverão compensar os prejuízos sofridos ${ }^{40}$.

A doutrina desenvolveu testes para tentar reconhecer essa prática. Os pioneiros, na tentativa de identificação do preço predatório, foram Philip Areeda e Donald Turner (1975) ${ }^{41}$. Para eles, em um estado de concorrência perfeita, os competidores tendem a maximizar seus lucros, praticando preços normalmente na mesma medida dos custos marginais, entendidos como os custos de uma unidade a mais produzida ${ }^{42}$. Quando o custo marginal é igual ao preço, sabe-se que foi vendido o último produto que era possível com lucro ${ }^{43}$. Assim sendo, se há uma venda a preço inferior ao custo de transação, tal conduta não é compatível com o objetivo de maximização dos lucros, só podendo ser explicada a partir do intuito predatório ${ }^{44}$.

Na aplicação prática de tal teoria, verificou-se um grande entrave, tendo em vista a dificuldade de cálculo dos chamados custos marginais ${ }^{45}$. Em função disso, buscou-se um substituto no chamado custo variável médio, que mediria a média dos custos variáveis de

\footnotetext{
${ }^{38}$ HOVENKAMP, Herbert. Antitrust. 3. ed. St. Paul: West, 1999, p. 118, tradução livre de “a firm’s attempt to drive a competitor out of business, or to discourage a potential competitor from entering the market, by selling its output at an artificially low price”.

${ }^{39}$ FORGIONI, Paula A. Os fundamentos do antitruste. São Paulo: RT, 1998, p. 314.

${ }^{40}$ FORGIONI, Paula A. Os fundamentos do antitruste. São Paulo: RT, 1998, p. 315.

${ }^{41}$ FAGUNDES, Jorge e KANCZUK, Fabio. Preços predatórios: testes e avanços recentes. Revista do IBRAC, São Paulo, v. 13, n 2, p. 38, 2006.

${ }^{42}$ HOVENKAMP, Herbert. Antitrust. 3. ed. St. Paul: West, 1999, p. 59.

43 SALOMÃO FILHO, Calixto. Direito concorrencial: as condutas. São Paulo: Malheiros, 2003, p. 162.

${ }^{44}$ FAGUNDES, Jorge e KANCZUK, Fabio. Preços predatórios: testes e avanços recentes. Revista do IBRAC, São Paulo, v. 13, n. 2, p. 38, 2006; HOVENKAMP, Herbert. Antitrust. 3. ed. St. Paul: West, 1999, p. 119; SALOMÃO FILHO, Calixto. Direito concorrencial: as condutas. São Paulo: Malheiros, 2003, p. 162; GELLHORN, Ernest e KOVACIC, William E. Antitrust law and economics. 4 ed. St. Paul: West Group, 1994, p. 138.

${ }^{45}$ FAGUNDES, Jorge e KANCZUK, Fabio. Preços predatórios: testes e avanços recentes. Revista do IBRAC, São Paulo, v. 13, n. 2, p. 38, 2006.

PRISMAS: Dir., Pol.Pub. e Mundial., Brasília, v.4, n, 1, p 194-214, jan/jul. 2007 
produção total, divida pelo número de bens produzidos ${ }^{46}$. Mesmo com tais simplificações, tal teoria não ficou imune à críticas, dando origem a novas teorias.

A partir das críticas à primeira teoria, desenvolveu-se o teste de Joskow e Klevorick, pelo qual se aplica comparação de preços e custos apenas se as estruturas do mercado indicarem que pode haver prejuízo para a concorrência ${ }^{47}$. Deve-se analisar o poder de mercado da empresa dominante, o tamanho das outras, a estabilidade do poder de mercado, a lucratividade da empresa dominante, as elasticidades residuais da demanda e, sobretudo as barreiras à entrada. Se não houver barreiras à entrada de novos competidores, a prática do preço predatório não terá sucesso, porquanto o ingresso de novos concorrentes impedirá a recuperação dos prejuízos sofridos.

Superada a questão estrutural, poderia se verificar a prática do preço predatório, analisando-se os custos e os comportamentos do agente, como por exemplo, a possibilidade de recuperação das perdas no mercado. Assim, se os preços são inferiores aos custos variáveis médios ou aos custos totais médios, tal prática deve ser considerada, a princípio, ilegal, porquanto tais práticas não se coadunariam com o objetivo de maximização da riqueza.

Outra teoria propõe a análise da relação entre os custos e os preços, mas usando o custo total médio, associado a qualquer evidência de intenção predatória. Tal evidência pode decorrer de um preço praticado ou mesmo de documentos que denotem a intenção na conduta realizada.

Para Richard Posner, o preço predatório é aquele praticado com a intenção de eliminar um concorrente igual ou mais forte apenas ${ }^{48}$. Para ele tal prática só ocorreria nos casos de venda abaixo dos custos marginais de curto prazo, ou no caso de vendas abaixo dos custos marginais de longo prazo, entendendo este último como o mais adequado para a apuração da conduta predatória, sem esquecer da intenção ${ }^{49}$. Todavia, ele não explica como se poderá provar essa intenção.

Outra linha de análise não se concentra na comparação de custos e preços, mas considera preço predatório a elevação da produção após a entrada de um novo concorrente no

\footnotetext{
${ }^{46}$ SALOMÃO FILHO, Calixto. Direito concorrencial: as condutas. São Paulo: Malheiros, 2003, p. 163; GELLHORN, Ernest e KOVACIC, William E. Antitrust law and economics. 4 ed. St. Paul: West Group, 1994, p. 138.

${ }^{47}$ FAGUNDES, Jorge e KANCZUK, Fabio. Preços predatórios: testes e avanços recentes. Revista do IBRAC, São Paulo, v. 13, n. 2, p. 38, 2006.

${ }^{48}$ POSNER, Richard. Antitrust Law: an economic perspective. Chicago: University of Chicago, 1976, p. 188.

${ }^{49}$ POSNER, Richard. Antitrust Law: an economic perspective. Chicago: University of Chicago, 1976, p. 189190.

PRISMAS: Dir., Pol.Pub. e Mundial., Brasília, v.4, n, 1, p 194-214, jan/jul. 2007 
mercado ${ }^{50}$.Tal interpretação pode ser chamada de regra da restrição do produto. Tal regra é mais eficiente para identificar bloqueios de novas entradas no mercado, do que preços predatórios $^{51}$.

Modernamente, novas linhas foram desenvolvidas chegando-se a negar a racionalidade da prática de preços predatórios, pelo que deveria ser ignorada ${ }^{52}$. Todavia, tal concepção restou superada, entendendo-se que a conduta predatória faz sentido econômico, havendo diferentes formas para identificá-la ${ }^{53}$.

Para o CADE - Conselho Administrativo de Defesa Econômica, por meio da resolução 20/99, a prática do preço predatório exige três condições: a) a fraqueza das concorrentes; b) existência de barreiras ao regresso ao mercado; c) os lucros a serem auferidos no futuro devem superar as perdas. Além desses elementos, usa-se o critério de Areeda e Turner, exigindo-se que os preços praticados sejam inferiores aos custos variáveis médios, nos termos da Portaria 70/2002 da SEAE - Secretaria de Acompanhamento Econômico. Portanto, no Brasil usa-se para a identificação do preço predatório o teste de Areeda Turner ampliado.

A partir desses elementos, pode-se afirmar, com certeza que, a prática do dumping não se confunde com o preço predatório o que, já vem sendo reconhecido pelo próprio CADE - Conselho Administrativo de Defesa Econômica ${ }^{54}$. Reitere-se que no conceito de dumping não é essencial o intuito predatório, nem a venda abaixo dos custos de produção ${ }^{55}$, mas sim a discriminação de preços entre diferentes mercados. A definição jurídica do dumping, conforme já visto, é dada pelo artigo VI do GATT 1994 que dispõe:

Para as finalidades do presente acordo, considera-se haver prática de dumping, isto é, oferta de um produto no comércio de outro país a preço inferior ao seu valor normal, no caso de o preço de exportação do produto ser inferior àquele praticado, no curso normal das atividades comerciais, para o mesmo produto quando destinado ao consumo do país exportador.

50 OLIVEIRA, Gesner e RODAS, João Grandino. Direito e economia da concorrência. Rio de Janeiro: Renovar, 2004, p. 60.

${ }^{51}$ FAGUNDES, Jorge e KANCZUK, Fabio. Preços predatórios: testes e avanços recentes. Revista do IBRAC. São Paulo, v. 13. n. 2, p. 40, 2006.

52 GELLHORN, Ernest e KOVACIC, William E. Antitrust law and economics. 4 ed. St. Paul: West Group, 1994, p. 138.

${ }^{53}$ FAGUNDES, Jorge e KANCZUK, Fabio. Preços predatórios: testes e avanços recentes. Revista do IBRAC. São Paulo, v. 13. n. 2, p. 43, 2006.

${ }^{54}$ CADE. Representação 72/93, de $1^{\text {o }}$ de outubro de 1997, acórdão publicado no DOU de 16 de outubro de 1997, Seção I, p. 23385.

${ }^{55}$ BARRAL, Welber. Dumping e comércio internacional: a regulamentação antidumping após a Rodada Uruguai. Rio de Janeiro: Forense, 2000, p. 159.

PRISMAS: Dir., Pol.Pub. e Mundial., Brasília, v.4, n, 1, p 194-214, jan/jul. 2007 
Com efeito, pode haver a prática concomitante das duas condutas, como no caso do produtor estrangeiro que exporta com dumping, usando um preço artificialmente baixo, pretendendo eliminar a concorrência ${ }^{56}$. Todavia, também pode não haver qualquer relação entre tais condutas, quando o produtor tem o monopólio no mercado nacional e vende a preço elevados no mercado interno e exporta com dumping, ou também no caso de uma venda a preços baixos, apenas em razão do excesso de estoques. Nesses casos, pode-se verificar que tais práticas não se confundem, representando cada qual uma realidade distinta, apesar de existir muita confusão sobre o assunto.

Em primeiro lugar, a prática de dumping está relacionada ao comércio internacional e deve ser tratada por autoridades ligadas ao comércio internacional, no caso do Brasil à SECEX - Secretaria de Comércio Exterior. Já o preço predatório está ligado à defesa da ordem econômica interna. O CADE - Conselho Administrativo de Defesa Econômica tem competência para analisar a prática preço predatório, mas não a prática do dumping, salvo se o país de origem das mercadorias não for membro da $\mathrm{OMC}^{57}$.

As diferenças não param por aí, como já ressaltado, o dumping também não exige a intenção de eliminar a concorrência ou aumentar arbitrariamente os lucros, o que torna o padrão de prova no preço predatório mais rigoroso que no dumping ${ }^{58}$. Além disso, é certo que a punição do preço predatório tem por objetivo a proteção do consumidor, já a punição do dumping tem por objetivo a proteção da indústria nacional ${ }^{59}$.

\section{Dumping e underselling}

O underselling é conhecido, normalmente, como a venda de produtos abaixo do seu preço de custo $^{60}$, independentemente da intenção. Ao contrário da prática do preço predatório, que exige uma intenção de eliminar a concorrência ou maximizar lucros, o underselling representa apenas e tão somente a prática objetiva de venda de produtos por

\footnotetext{
${ }^{56}$ BARRAL, Welber. Dumping e comércio internacional: a regulamentação antidumping após a Rodada Uruguai. Rio de Janeiro: Forense, 2000, p. 157.

57 OLIVEIRA, Gesner e RODAS, João Grandino. Direito e economia da concorrência. Rio de Janeiro: Renovar, 2004, p. 73; BARRAL, Welber. Dumping e comércio internacional: a regulamentação antidumping após a Rodada Uruguai. Rio de Janeiro: Forense, 2000, p. 160.

58 OLIVEIRA, Gesner e RODAS, João Grandino. Direito e economia da concorrência. Rio de Janeiro: Renovar, 2004, p. 73.

59 OLIVEIRA, Gesner e RODAS, João Grandino. Direito e economia da concorrência. Rio de Janeiro: Renovar, 2004, p. 74.

${ }^{60}$ BARRAL, Welber. Dumping e comércio internacional: a regulamentação antidumping após a Rodada Uruguai. Rio de Janeiro: Forense, 2000, p. 157. 
preço inferior ao seu preço de custo. Além disso, é certo que no preço predatório não se precisa chegar a um preço inferior ao preço de custo, mas apenas a um preço baixo, por exemplo, com uma grande redução da margem de lucro, visando apenas a eliminação dos conceitos. Por fim, vale ressaltar que o underselling nem sempre é punível pelas normas de direito econômico interno, ao passo que o preço predatório normalmente o é ${ }^{1}$.

Vale a pena, repetir que no conceito de dumping não é essencial o intuito predatório, nem a venda abaixo dos custos de produção ${ }^{62}$, mas sim a discriminação de preços entre diferentes mercados. Daí já se vê as diferenças. Em primeiro lugar, a prática de dumping está relacionada ao comércio internacional e o underselling é ligado ao comércio interno ${ }^{63}$. As diferenças não param por aí, como já ressaltado, no dumping não é essencial a venda a preços abaixo do custo de produção, mas apenas a venda a preços inferiores ao valor normal praticado no país exportador. Logo, mais uma vez deve ser descartada qualquer identificação entre as duas citadas práticas.

\section{Dumping e subsídios}

Por vezes a exportação de um produto se dá por um baixo preço em virtude de uma intervenção estatal que concedendo certos benefícios, acaba puxando o preço para baixo. Nesse caso, não há que se falar em prática de dumping, mas sem em concessão de subsídios, que possui contornos próprios.

Os subsídios representam, em última análise, considerando o teor do Acordo sobre subsídios e medidas compensatórias (ASMC), a concessão de vantagens por meio de uma contribuição governamental, envolvendo o repasse direto de fundos ou de obrigações, a transferência de mercadorias ou de serviços feita pelo próprio Estado, ou em seu nome, além daqueles que compõem a infra-estrutura geral ${ }^{64}$. Estão abrangidos nesse conceito também incentivos fiscais, renúncias de receitas públicas ou qualquer forma de sustentação ao preço

\footnotetext{
${ }^{61}$ BARRAL, Welber. Dumping e comércio internacional: a regulamentação antidumping após a Rodada Uruguai. Rio de Janeiro: Forense, 2000, p. 160.

62 BARRAL, Welber. Dumping e comércio internacional: a regulamentação antidumping após a Rodada Uruguai. Rio de Janeiro: Forense, 2000, p. 159.

63 OLIVEIRA, Gesner e RODAS, João Grandino. Direito e economia da concorrência. Rio de Janeiro: Renovar, 2004, p. 73; BARRAL, Welber. Dumping e comércio internacional: a regulamentação antidumping após a Rodada Uruguai. Rio de Janeiro: Forense, 2000, p. 160.

${ }^{64}$ COSTA, Lígia Maura. Subsídios e Salvaguardas. In: AMARAL JÚNIOR, Alberto do (Coord). OMC e o comércio internacional. São Paulo: Aduaneiras, 2002, p. 64.

PRISMAS: Dir., Pol.Pub. e Mundial., Brasília, v.4, n, 1, p 194-214, jan/jul. 2007 
do produto. Na idéia de subsídios é fundamental a contribuição ou apoio do Estado, além da especificidade, isto é, de um benefício para o produtor ou para o setor produtivo específico ${ }^{65}$.

Os subsídios podem ser classificados de três formas distintas: proibidos, recorríveis e irrecorríveis. Vale a pena destacar que tal classificação não se aplica integralmente aos produtos agrícolas, na medida em que há uma regulamentação específica sobre a matéria no acordo agrícola da OMC.

Os subsídios não recorríveis são aqueles permitidos pelo Acordo de subsídios e medidas compensatórias (ASMC), pois não restringem, nem geram distorções no comércio internacional ${ }^{66}$. Nessa categoria, estão abrangidos tanto os subsídios gerais, tais como gastos com educação ou infra-estrutura, como subsídios específicos que sejam concedidos para auxiliar pesquisas, ajudar determinadas regiões ou ainda auxiliar processo de adaptação ambiental $^{67}$. Neste último caso, os subsídios devem ser limitados a $20 \%$ dos custos da adaptação.

Os subsídios recorríveis são aqueles que podem gerar efeitos desfavoráveis a outro país, como danos a produção nacional, anulação de vantagens já consolidadas ou mesmo quaisquer prejuízos graves aos interesses de outro país membro da OMC ${ }^{68}$. Por fim, os subsídios proibidos estão vinculados ao desempenho exportador do país e ao incentivo no uso de mercadorias nacionais, em detrimento das mercadorias importadas ${ }^{69}$. Como o próprio título já deixa claro, tais subsídios não podem ser usados pelos países membros da OMC (ASMC - art. $3^{\circ}, \S 2^{\circ}$ ), porquanto representam, a princípio, uma distorção do comércio internacional.

O próprio ASMC reconhece que os subsídios podem representar um papel fundamental para programas de desenvolvimento econômico dos países em desenvolvimento (ASMC - art. 27) e, por isso, outorga a tais países um tratamento diferenciado. Assim, os países em desenvolvimento que se enquadrem no anexo VII do ASMC podem adotar os

65 TREBILCOCK, M. J. ; HOWSE, Robert. The regulation of international trade. 2. ed. London: Routledge, 2001, p. 195; CHEREM, Giselda da Silveira. Subsídios. In: BARRAL, Welber (Org.) O Brasil e a OMC. 2. ed. Curitiba: Juruá, 2004, p. 235.

${ }^{66}$ COSTA, Lígia Maura. Subsídios e Salvaguardas. In: AMARAL JÚNIOR, Alberto do (Coord). OMC e o comércio internacional. São Paulo: Aduaneiras, 2002, p. 66.

${ }^{67}$ TREBILCOCK, M. J. ; HOWSE, Robert. The regulation of international trade. 2. ed. London: Routledge, 2001, p. 196.

${ }^{68}$ MAC DONNEL, Stella Maris. El comercio internacional desleal. Rosario: Aplicación Tributaria, 1997, p. 83; COSTA, Lígia Maura. Subsídios e Salvaguardas. In: AMARAL JÚNIOR, Alberto do (Coord). OMC e o comércio internacional. São Paulo: Aduaneiras, 2002, p. 66.

${ }^{69}$ CHEREM, Giselda da Silveira. Subsídios. In: BARRAL, Welber (Org.) O Brasil e a OMC. 2. ed. Curitiba: Juruá, 2004, p. 235; COSTA, Lígia Maura. Subsídios e Salvaguardas. In: AMARAL JÚNIOR, Alberto do (Coord). OMC e o comércio internacional. São Paulo: Aduaneiras, 2002, p. 65.

PRISMAS: Dir., Pol.Pub. e Mundial., Brasília, v.4, n, 1, p 194-214, jan/jul. 2007 
chamados subsídios proibidos. Os outros países em desenvolvimento também é admitida a adoção de tais subsídios pelo prazo de 8 anos, desde que não elevem os níveis dos subsídios a exportações. Em relação aos subsídios que incentivam o uso dos produtos nacionais em detrimento dos produtos estrangeiros, o prazo de carência será de 5 anos, contados da entrada em vigor da OMC, para os países em desenvolvimento e 8 anos para os países de menor desenvolvimento relativo ${ }^{70}$.

A concessão desses prazos de adaptação representa uma manifestação do princípio da desigualdade compensadora, porquanto visa a permitir um maior desenvolvimento de todos os países membros da $\mathrm{OMC}^{71}$. Juridicamente tais países são considerados mais fracos e, por isso, deve-se lhes dar condições de se adaptar às regras de direito internacional econômica de forma mais gradativa, permitindo um tentativa de melhor desenvolvimento para redução das desigualdades. Todavia, a maioria dos prazos de adaptação já passou, sem que houvesse uma redução efetiva de tais diferenças ${ }^{72}$.

De qualquer modo, é certo que a concessão de subsídios não se confunde com a prática do dumping. Como já restou destacado, a prática dos subsídios envolve uma atuação estatal, com a transferência direta ou indireta de recursos ou a concessão de incentivos, para tornar os preços mais competitivos. Já o dumping é uma prática exclusivamente privada que decorre da atuação apenas do empresário, sem qualquer atuação estatal ${ }^{73}$.

\section{Novos tipos de dumping?}

Modernamente, há algumas tentativas no sentido de ampliar o conceito de dumping, para abranger novos tipos de situações, que decorrem fundamentalmente de diferenças econômico-sociais entre os países desenvolvidos e os países em desenvolvimento $^{74}$. Os novos tipos seriam o dumping cambial, o ambiental e o social.

O dumping cambial se configuraria pela manutenção de taxas cambiais que desvalorizassem a moeda nacional, de modo que os produtos importados ficariam muito caros

${ }^{70}$ COSTA, Lígia Maura. Subsídios e Salvaguardas. In: AMARAL JÚNIOR, Alberto do (Coord). OMC e o comércio internacional. São Paulo: Aduaneiras, 2002, p. 65.

${ }^{71}$ MARGARIDA, Karla. Subsídios sob a ótica do direito internacional econômico. Revista do Programa de Mestrado em Direito do UniCEUB, Brasília, v. 2, n.2, p. 194, jul-dez/2005.

${ }^{72}$ VARELLA, Marcelo Dias. Direito internacional econômico ambiental. Belo Horizonte: Del Rey, 2003, p. 153.

${ }^{73}$ ARRUDA, Gustavo Fávaro. Entendendo o dumping e o direito antidumping. Revista do IBRAC, São Paulo, V. 12, n. 6, p. 21.

${ }^{74}$ ARRUDA, Gustavo Fávaro. Entendendo o dumping e o direito antidumping. Revista do IBRAC, São Paulo, v. 12, n. 6, p. 15-16, 2005; BARRAL, Welber. Dumping e comércio internacional: a regulamentação antidumping após a Rodada Uruguai. Rio de Janeiro: Forense, 2000, p. 13.

PRISMAS: Dir., Pol.Pub. e Mundial., Brasília, v.4, n, 1, p 194-214, jan/jul. 2007 
e os produtos exportados seriam mais baratos, facilitando a exportação dos mesmos que chegariam no mercado externo a um preço relativamente mais baixo ${ }^{75}$. Tome-se o exemplo de venda de produtos brasileiros para os Estados Unidos, antes da desvalorização do real, pelo valor de US\$ 10,00 (dez dólares), considerando o produto vendido no Brasil por R\$ 10,00 (dez reais). Com a desvalorização do real que não afetaria o preço do produto no Brasil, o qual se manteria em $\mathrm{R} \$ 10,00$ (dez reais), a mesma mercadoria passou a ser vendida por US\$ 5,00 (cinco dólares) no mercado americano, afetando fortemente os competidores no mercado americano.

É certo que tal realidade existe, mas não pode ser enquadrada como dumping, diante da atual conceituação da legislação pertinente. A existência do dumping pressupõe a venda abaixo do preço normal e, nesses casos, o preço não será inferior ao normal no país de origem da mercadoria. Mesmo com a desvalorização da moeda brasileira, o valor normal do produto não seria superior ao seu preço de exportação. Não há nesse caso, qualquer discriminação de preços, afastando-se, por conseguinte, do conceito clássico de dumping ${ }^{76}$.

O dumping ambiental seria a redução do preço de certas mercadorias em razão da inexistência ou da existência de menores exigências ambientais para a sua produção. Tal prática se relaciona normalmente com a transferência de indústrias poluentes para os países em desenvolvimento, em geral menos rígidos em relação ao meio-ambiente ${ }^{77}$. Diz-se que o dumping ambiental decorreria de uma "vantagem comparativa ilícita advinda da degradação ambiental, nos países em desenvolvimentos”78. Afirma-se que tal redução de custos, em detrimento da proteção do meio ambiente, seria algo equivalente a concessão de subsídios injustos para a exportação ${ }^{79}$.

Imagine-se a situação de um produto cujo custo de produção seja de US\$ 50,00 (cinqüenta dólares). Em relação a tal mercadoria, a legislação de determinado país impõe o tratamento dos resíduos dessa produção, bem como a instalação de equipamentos que reduzam a emissão de poluentes no ar, gerando um aumento de US\$ 25,00 (vinte e cinco dólares) nos custos do referido produto, que será negociado a US\$ 75,00 (setenta e cinco

\footnotetext{
${ }^{75}$ CRESPO B., Raul. La práctica del dumping y los fundamentos del antidumping. Revista Venezolana de Análisis de Coyuntura, v. 3, n. 2, p. 58, jul-dic/1997.

${ }^{76}$ CRESPO B., Raul. La práctica del dumping y los fundamentos del antidumping. Revista Venezolana de Análisis de Coyuntura, v. 3, n. 2, p. 58, jul-dic/1997.

${ }^{77}$ BARRAL, Welber. Dumping e comércio internacional: a regulamentação antidumping após a Rodada Uruguai. Rio de Janeiro: Forense, 2000, p. 13.

${ }^{78}$ GOYOS JÚNIOR, Durval Noronha et al. Tratado de defesa comercial: antidumping, compensatórias e salvaguardas. São Paulo: Observador Legal, 2003, p. 285.

${ }^{79}$ STEIL, Benn. The new rules of trade. National Review, v. 46 Issue 7, 18/4/1994, p. 41.

PRISMAS: Dir., Pol.Pub. e Mundial., Brasília, v.4, n, 1, p 194-214, jan/jul. 2007 
dólares), ignorando-se outros custos e os lucros. Ocorre que em outro país, não há legislação que imponha o tratamento dos resíduos, nem a instalação de equipamentos que evitem ou reduzam a poluição do ar. Nesse caso, considerando os mesmos custos de produção, ignorando-se outros custos e os lucros, o produto poderia ser vendido a US\$ 50,00 (cinqüenta dólares) para o mercado daquele país no qual há todas as regras protetivas, prejudicando os correntes ali situados que são obrigados a obedecê-las.

Com efeito, há certo descaso ou uma menor preocupação ambiental, em alguns países que, diminuindo as exigências de preservação ambiental, acabam por diminuir os custos de produção, permitindo a venda de mercadorias a preços mais baixos do que o das mercadorias similares em outros países. Há, sem dúvida, um aumento de competitividade que pode ser ilegítimo ${ }^{80}$, gerando prejuízos para o meio ambiente. Todavia, mais uma vez a mercadoria não é vendida por um preço inferior ao seu preço normal no país, isto é, é o preço normal que é mais baixo do que em outros países e, por isso, não se pode enquadrar tal conduta como dumping diante da legislação de regência.

Por fim, resta tratar do dumping social que representaria a "vantagem comparativa derivada da superexploração de mão de obra nos países em desenvolvimento”81. Nessa linha de compreensão, o dumping seria realizado em razão dos custos inferiores da mão de obra e das menores garantias trabalhistas no país, que também seriam capazes de baratear o custo dos produtos. Em tal situação, os custos mais baixos do trabalho representariam, em tese, uma distorção da concorrência ${ }^{82}$, na medida em que permitiram a venda de produtos a preços bem mais baixos do que aqueles produzidos em condições que tenham que obedecer a todas as garantias trabalhistas.

Mais uma vez tal conduta não representa um dumping no conceito dado pelo artigo 2.1 do Acordo Antidumping, porquanto não se vende a mercadoria a preço mais baixo que o seu preço normal. Trata-se, na verdade do aproveitamento de vantagens dos custos comparativos e não de uma política de $\operatorname{preços}^{83}$. Além disso, é certo que a imposição de

${ }^{80}$ GOYOS JÚNIOR, Durval de Noronha. et al. Tratado de defesa comercial: antidumping, compensatórias e salvaguardas. São Paulo: Observador Legal, 2003, p. 285-6; JOHANNPETER, Guilherme. Antidumping: prática desleal no comércio internacional. Porto Alegre: Livraria do Advogado, 1996, p. 87; BARRAL, Welber Oliveira. Dumping e comércio internacional: a regulamentação antidumping após a rodada Uruguai. Rio de Janeiro: Forense, 2000, p. 13.

${ }^{81}$ BARRAL, Welber. Dumping e comércio internacional: a regulamentação antidumping após a Rodada Uruguai. Rio de Janeiro: Forense, 2000, p. 14.

${ }^{82}$ STEIL, Benn. The new rules of trade. National Review, v. 46 Issue 7, 18/4/1994, p. 40.

83 ROJAS AMANDI, Victor Manuel. El derecho antidumping de la Unión Europea. México: Porruá, 2004, p. 17; CRESPO B., Raul. La práctica del dumping y los fundamentos del antidumping. Revista Venezolana de Análisis de Coyuntura, v. 3, n. 2, p. 59, jul-dic/1997.

PRISMAS: Dir., Pol.Pub. e Mundial., Brasília, v.4, n, 1, p 194-214, jan/jul. 2007 
direitos antidumping no caso beneficiaria apenas o país comprador e seus produtores, em nada beneficiaria os próprios trabalhadores que poderiam até perder seus empregos ${ }^{84}$.

Em qualquer desses casos citados, o preço baixo decorre de uma política do Estado que não dá tantas garantias trabalhistas ou que não faz tantas exigências ambientais. Não se trata de uma política privada de discriminação de preços. O reconhecimento da prática do dumping, além de esbarrar na própria conceituação legal, é visto com maus olhos pelos países em desenvolvimento. Eles entendem que a busca da configuração de tais situações como dumping representa uma tentativa dos países desenvolvidos de criar barreiras protecionistas nos seus mercados, impedindo o ingresso dos produtos dos países em desenvolvimento, barrando sua crescente participação no mercado mundial ${ }^{85}$.

Artigo recebido em março de 2007

Aceito para publicação em abril de 2007

\section{Referências}

ALLEN, Robert (publishing Director). Essential English Dictionary. São Paulo: Chambers Martins Fontes, 1999.

ARRUDA, Gustavo Fávaro. Entendendo o dumping e o direito antidumping. Revista do IBRAC, São Paulo, Volume 12, número 6, p. 9-42, jul./set. 2005.

BAPTISTA, Luiz Olavo. Dumping e Anti-dumping no Brasil. In: AMARAL JÚNIOR, Alberto do (coord). OMC e o comércio internacional. São Paulo: Aduaneiras, 2002.

BARRAL, Welber. Medidas Antidumping. In: (Org). O Brasil e a OMC. 2. ed. Curitiba: Juruá, 2004.

BARRAL, Welber Oliveira. Dumping e comércio internacional: a regulamentação antidumping após a rodada Uruguai. Rio de Janeiro: Forense, 2000.

CHEREM, Giselda da Silveira. Subsídios. In: BARRAL, Welber (org.) O Brasil e a OMC. 2. ed. Curitiba: Juruá, 2004.

\footnotetext{
${ }^{84}$ GOYOS JÚNIOR, Durval Noronha et al. Tratado de defesa comercial: antidumping, compensatórias e salvaguardas. São Paulo: Observador Legal, 2003, p. 285; ROJAS AMANDI, Victor Manuel. El derecho antidumping de la Unión Europea. México: Porruá, 2004, p. 17.

${ }^{85}$ ARRUDA, Gustavo Fávaro. Entendendo o dumping e o direito antidumping. Revista do IBRAC, São Paulo, Volume 12, número 6, 2005, p. 16.

PRISMAS: Dir., Pol.Pub. e Mundial., Brasília, v.4, n, 1, p 194-214, jan/jul. 2007 
COSTA, Lígia Maura. Subsídios e Salvaguardas. In: AMARAL JÚNIOR, Alberto do (coord). OMC e o comércio internacional. São Paulo: Aduaneiras, 2002.

CRESPO B., Raul. La práctica del dumping y los fundamentos del antidumping. Revista Venezolana de Análisis de Coyuntura. Caracas: Venezuela, Vol. III, No. 2, p. 55-81, juldic/1997.

CRETELLA JÚNIOR, José. Comentários à lei antitruste. 2.ed. Rio de Janeiro: Forense, 1996.

FAGUNDES, Jorge e KANCZUK, Fabio. Preços predatórios: testes e avanços recentes. Revista do IBRAC, São Paulo, Volume 13, número 2, p. 37-61, 2006.

FORGIONI, Paula A. Os fundamentos do antitruste. São Paulo: Revista dos Tribunais, 1998.

GAGLIANO, Pablo Stolze e PAMPLONA FILHO, Rodolfo. Novo curso de Direito Civil: parte geral. 2. ed. São Paulo: Saraiva, 2002, v. 1.

GELLHORN, Ernest e KOVACIC, William E. Antitrust law and economics. 4 ed. St. Paul: West Group, 1994.

GOYOS JÚNIOR, Durval Noronha et al. Tratado de defesa comercial: antidumping, compensatórias e salvaguardas. São Paulo: Observador Legal, 2003.

GUEDES, Josefina Maria M. M. e PINHEIRO, Sílvia M. Antidumping, subsídios e medidas compensatórias. 3. ed. São Paulo: Aduaneiras, 2002.

HOWSE, Robert. The regulation of international trade. 2. ed. London: Routledge, 2001

HOEKMAN, Bernard M.; KOSTECKI, Michel M. The political economy of the world trading system: the WTO and beyond. 2 ed. Oxford: University Press, 2001.

HOVENKAMP, Herbert. Antitrust. 3. ed. St. Paul: West, 1999.

JOHANNPETER, Guilherme Chagas Gerdau. Antidumping: prática desleal no comércio internacional. Porto Alegre: Livraria do Advogado, 1996.

LEÃES, Luiz Gastão Paes de Barros. O “dumping” como forma de abuso do poder econômico. Revista de Direito Mercantil, Industrial, Econômico e Financeiro. São Paulo, v. 32, n. 91, p. 5-15, jul./set. 1993.

MAC DONNEL, Stella Maris. El comercio internacional desleal. Rosario: Aplicación Tributaria, 1997.

MARCEAU, Gabrielle. Anti-dumping and anti-trust issues in free trade areas. Oxford: Clarendon Press, 1994.

MARGARIDA, Karla. Subsídios sob a ótica do direito internacional econômico. Revista do Programa de Mestrado em Direito do UniCEUB, Brasília, v. 2, n.2, p. 178-201, juldez/2005 
MARQUES, Frederico do Valle Magalhães. O “Dumping” na Organização Mundial do Comércio e no Direito Brasileiro - Decreto 1.602/65. In: CASELLA, Paulo Borba e MERCADANTE, Araminta de Azevedo (coord). Guerra comercial ou integração mundial pelo comércio? A OMC e o Brasil. São Paulo: Ltr, 1998.

OLIVEIRA, Gesner e RODAS, João Grandino. Direito e economia da concorrência. Rio de Janeiro: Renovar, 2004.

OSTONI, Lucia. Anti-dumping circumvention in the EU and the US: is there a future for multilateral provisions under the WTO? Fordham Journal of Corporate \& Financial Law. Vol. 10 Issue 2, p. 407-438, 2005.

POPP, Carlyle e ABDALA, Edson Vieira. Comentários à nova lei antitruste. 2 ed. Curitiba: Juruá, 1997.

POSNER, Richard. Antitrust Law: an economic perspective. Chicago: University of Chicago, 1976.

PINTO, Carlos Alberto da Mota. Teoria geral do Direito Civil. 3. ed. Coimbra: Coimbra, 1999.

RÁO, Vicente. Ato jurídico. 4. ed. São Paulo: RT, 1997.

ROJAS AMANDI, Victor Manuel. El derecho antidumping de la Unión Europea. México: Porruá, 2004.

SALOMÃO FILHO, Calixto. Direito concorrencial: as condutas. São Paulo: Malheiros, 2003.

STEIL, Benn. The new rules of trade. National Review, Vol. 46 Issue 7, p. 40-44, 18/4/1994.

TREBILCOCK, M. J. ; HOWSE, Robert. The regulation of international trade. 2. ed. London: Routledge, 2001.

VARELLA, Marcelo Dias. Direito internacional econômico ambiental. Belo Horizonte: Del Rey, 2003.

VINER, Jacob. Dumping: a problem in international trade. Chicago: University of Chicago Press, 1923. 


\section{Resumo}

A definição dos exatos contornos do dumping é fundamental para aplicação de medidas antidumping, não devendo ser confundida com outras práticas. $\mathrm{O}$ termo dumping foi e ainda é usado em vários sentidos, nem sempre corretos e, por isso, é necessário afastar a confusão terminológica entre o dumping e outras práticas. Assim sendo, deve-se buscar o conceito adequado de dumping, para posteriormente realizar as distinções que se mostrarem necessárias Nesta linha, deve-se primeiro formular um conceito econômico e, posteriormente, um conceito jurídico do dumping. A partir daí, há como distinguir o dumping de outras práticas, como o preço predatório, o underselling e os subsídios. Também pode-se dizer que as práticas mais recentes, denominadas de dumping cambial, social e ambiental, não se enquadram no conceito do dumping.

Palavras-chave:

internacional. Dumping. Preço predatório. Underselling. Subsídios.

\section{Abstract}

The definition of the accurate contours of dumping is fundamental for the application of antidumping measures, which is not to be confused with others practices. The term dumping was and still is used with several meanings; not always correct and consequently there is a necessity to clear the terminologic confusion between dumping and others practices. Therefore, the adequate concept of dumping must be found and later on, adjust it with the necessary distinctions. With this in mind a economic concept must be formulated first, and later, a legal concept of dumping. From that it is possible to distinguish dumping from other practices, as predatory price, underselling and subsidies. It also can be said that the most recent practices named monetary, social and environmental dumping, do not qualify as dumping concepts.

Keywords: International trade. Dumping. Predatory price. Underselling. Subsidies. 